\title{
Influence of airtightness of steel sandwich panel joints on heat losses
}

\author{
Markus Kuhnhenne ${ }^{1, *}$, Vitali Reger ${ }^{1}$, Dominik Pyschny ${ }^{1}$, and Bernd Döring ${ }^{2}$ \\ ${ }^{1}$ RWTH Aachen University, Sustainable Metal Building Envelopes, 52074 Aachen, Mies-van-der-Rohe-Str. 1, Germany \\ ${ }^{2}$ FH Aachen University, Subject Area Building Services, 52066 Aachen, Bayernallee 9, Germany
}

\begin{abstract}
Energy saving ordinances requires that buildings must be designed in such a way that the heat transfer surface including the joints is permanently air impermeable. The prefabricated roof and wall panels in lightweight steel constructions are airtight in the area of the steel covering layers. The sealing of the panel joints contributes to fulfil the comprehensive requirements for an airtight building envelope. To improve the airtightness of steel sandwich panels, additional sealing tapes can be installed in the panel joint. The influence of these sealing tapes was evaluated by measurements carried out by the RWTH Aachen University - Sustainable Metal Building Envelopes. Different installation situations were evaluated by carrying out airtightness tests for different joint distances. In addition, the influence on the heat transfer coefficient was also evaluated using the Finite Element Method (FEM). The combination of obtained air volume flow and transmission losses enables to create an "effective heat transfer coefficient" due to transmission and infiltration. This summarizes both effects in one value and is particularly helpful for approximate calculations on energy efficiency.
\end{abstract}

\section{Introduction}

Energy efficient construction has become increasingly important in recent years. In particular, the requirements for thermal insulation and airtightness of roof and wall systems have a significant impact on the design and execution of building envelopes in lightweight metal construction.

In heated and well-insulated buildings, the heat transfer via leaks in the building envelope reaches a nonnegligible proportion. In addition to minimizing heat transmission, the airtightness of the building envelope is an essential property for creating energy-efficient and physically perfect buildings.

The German Energy Saving Ordinance stipulates "buildings to be constructed must be designed in such a way that the heat transfer surface, including joints, is permanently air-impermeable in accordance with the generally accepted rules of technology". The requirement for airtight building envelopes should help to avoid unnecessary heat transfer and structural damage. The airtightness layer is intended to prevent warm, moisture-laden air from flowing through building components. Leakage points in the airtightness layer can lead to condensation damage in the construction.

The prefabricated flat elements of the building envelopes in lightweight steel construction are absolutely airtight in the area of the metal cover layers. The sealing of the component joints contributes to continuing the sealing levels across element and construction section boundaries and fulfilling the comprehensive requirement of the Energy Saving Ordinance for an airtight building envelope. Therefore, compressible sealing bands have been established as the most common method to seal joints.

The purpose of this paper is to determine the influence of airtightness on heat losses. Therefore, laboratory tests of joints with and without additional sealing are combined with determined pressure differences across an exemplary building due to wind and temperature differences. An "effective heat transfer coefficient" can be identify which combines the air volume flow with the transmission losses and enable rough calculations on energy efficiency for the building. Finally, the energetic and economic performance is shown for exemplary U-values and joint leakages.

\section{Sandwich construction}

The steel sandwich construction method becomes more and more important in the last decades and is used worldwide as dominant cladding solution especially for industrial and commercial buildings. Approx. 200 million $\mathrm{m}^{2}$ of steel sandwich panels per year are installed in Europe. They are composed of individual, industrially produced sandwich panels. These elements are ready-toassemble roof and wall panels and consist of two thin metal cover layers, which are interconnected in a shearresistant manner via an insulation core. The insulation cores of sandwich panels are usually made of rigid

\footnotetext{
* Corresponding author: mku@stb.rwth-aachen.de
} 
polyurethane foam (PUR) or mineral wool (MW). The surfaces usually consist of steel face sheets and are available with lined, trapezoidal or corrugated profiles.

Historically, steel sandwich panel constructions were developed and optimized primarily with regard to structural and mechanical behaviour, with a shift in recent years toward thermal performance. Also airtightness aspects becomes more important to achieve energy efficient buildings [1].

Due to their design, steel sandwich panel joints are basically divided into eight groups in DIN EN 14509 [2], see Figure 1. Therefore, the formation of these joints is of particular importance.

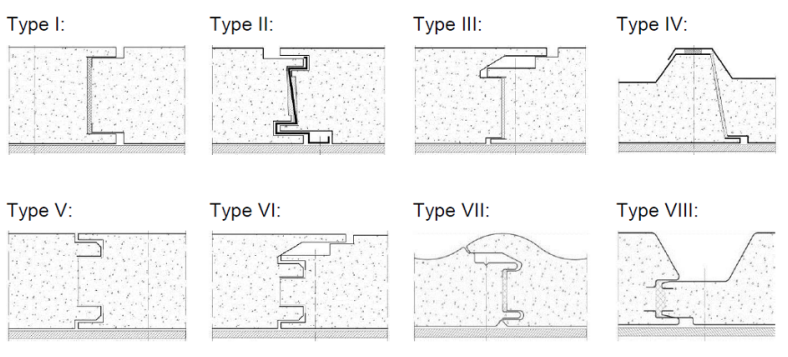

Fig. 1. Different types of steel sandwich joints according to EN 14509

\subsection{Thermal transmittance of a sandwich panel according to EN 14509}

The thermal performance of construction elements is characterised by several measures: thermal transmittance $\mathrm{U}$ in $\mathrm{W} /\left(\mathrm{m}^{2} \cdot \mathrm{K}\right)$, the linear thermal transmittance $\Psi$ in $\mathrm{W} /(\mathrm{m} \cdot \mathrm{K})$, and point thermal transmittance $\chi$ in $\mathrm{W} / \mathrm{K}[3]$. Using these characteristics, the influence of thermal bridges can be estimated [4]. Thermal performance is determined in accordance with EN ISO 10211 [5] using numerical approaches, supported by thermal imaging and other techniques to ascertain 'as-built' conditions.

The design value of the thermal transmittance of a sandwich panel according to the exact method of EN 14509 is given by consideration of the heat transfer coefficient including profile geometry of the panel and the thermal effect of the longitudinal joint in $\mathrm{W} /\left(\mathrm{m}^{2} \cdot \mathrm{K}\right)$. Therefore, the heat flow through the considered sandwich panel is determined by numerical calculations using the Finite Element Method (FEM). From this, the length-related heat transfer coefficient can be determined and the design value created.

\subsection{Airtightness of sandwich construction}

Airtightness is an important attribute for improved energy efficiency of building envelopes. Uncontrolled ventilation losses should be minimised, and the benefits of mechanical ventilation systems are greater if buildings are airtight. Moisture problems can also occur if warm, wet air can infiltrate into facades [6]. Laboratory tests regarding this problem are presented in another paper at NSB2020 [7].

Joint tightness is defined in DIN 4108-2 [8] and DIN 18542 [9]. A joint permeability coefficient at a pressure difference of $10 \mathrm{~Pa}$ between inside and outside of less than $0.1 \mathrm{~m}^{3} /\left(\mathrm{h} \cdot \mathrm{m} \cdot(\mathrm{daPa})^{2 / 3}\right)$ is there assessed as sufficiently leak-proof.

Evaluation of airtightness currently relies on experimental procedures. At building component level, airtightness test rigs are used to determine the a-value in $\mathrm{m}^{3} /\left(\mathrm{h} \cdot \mathrm{m} \cdot \mathrm{daPa}^{2 / 3}\right)$. The measuring principle of the stationary measuring method is shown in Figure 2.

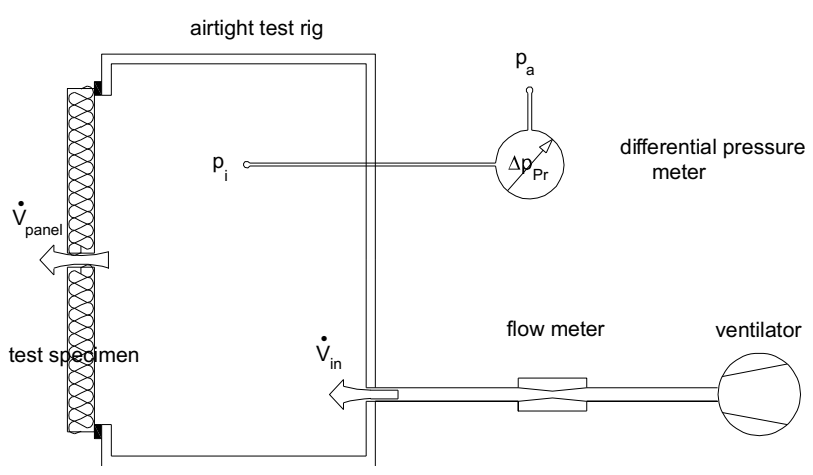

Fig. 2. Measuring principle of the stationary measuring method

In the stationary measuring method, a pressure difference $\left(\Delta \mathrm{p}_{\mathrm{Pr}}\right)$ between the interior of the test stand and the environment is generated with the aid of a fan and the required volume flow $\left(\mathrm{V}^{\cdot}\right.$ in $)$ conveyed by the fan is measured. At a constant pressure difference between the interior and the environment, the measured volume flow $\left(\mathrm{V}^{\cdot}{ }_{\text {in }}\right)$ is equal to the volume flow $\left(\mathrm{V}^{\cdot}\right.$ panel $)$ through the component to be tested, if the test stand itself does not show any leakage. For steel panels, this means that the volume flow $\mathrm{V}^{\cdot}$ panel can only flow through the component joint, since the elements are absolutely airimpermeable in the control range. The measurement is carried out for various pressure differentials (pressure stages) which are constant during the measurement.

As a result, the measurement method provides the correlation of pressure difference and volume flow, which can be plotted in a diagram. The relationship between air flow rate and pressure difference is usually non-linear, so that a double logarithmic scaling is usually selected for the diagram. The curve of the volume flows plotted over the test pressure differences in these scaling results in a straight line. The test pressure differences are determined in accordance with Appendix A of EN 12114 [10].

\section{Effective U-value}

The heat losses of a building component result from heat transmission (U-value taking into account thermal bridge effects) and infiltration due to joint leakage (see chapter 2).

In order to be able to determine the infiltration, the pressure differences across the respective building components must be known, whereby the driving forces are the wind pressure on the building envelope on the one hand and the thermal lift due to temperature differences between inside and outside on the other [11]. From this air volume flow, a U-value (heat transfer coefficient) can be formally determined by reference to 
$1 \mathrm{~m}^{2}$ of component surface if the temperature differences are known. Thus, the influence of the joint tightness on the energy efficiency is easily recognisable and directly related to the transmission.

Combining this influence of the air volume flow with the transmission losses, an "effective heat transfer coefficient" due to transmission and infiltration can be calculated, which combines both effects in one value and is particularly helpful for rough calculations on energy efficiency.

\subsection{Determination of infiltration}

The contribution of the structural joints to the infiltration air exchange depends not only on the joint tightness but also on the pressure differences across the individual structural element due to wind and temperature differences (additional pressure differences that may result from the use of mechanical ventilation systems are not taken into account here). These pressure differences in turn depend on the building geometry, the environment and the weather.

In order to arrive at a meaningful estimation, typical dimensions for a hall-like building (45 m x $30 \mathrm{~m} \mathrm{x} 8 \mathrm{~m}$ ) are used on the one hand, and on the other hand a weather data set (Test Reference Year TRY) from the German meteorological service for the Aachen location is used, which is also valid for the Rhine and Ruhr conurbation areas and is therefore relevant for many projects.

The pressure coefficients from EN 1991-4 [12], [13] were used to determine the wind pressures. In conjunction with the directions of inflow from wind speeds of the used weather data, the pressures on the building envelope from the outside can be determined, see Figure 3.

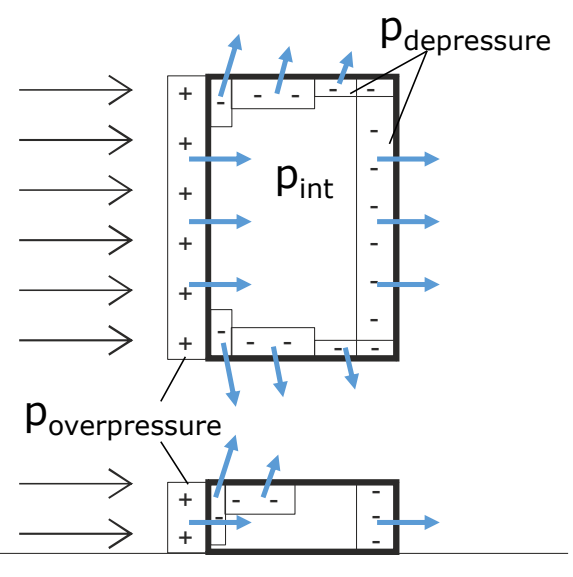

Fig. 3. Pressures (+/-) from the outside and flow through (blue arrows) the building envelope, schematic diagram for exemplary situation, above: floor plan, below: section

In the building an internal pressure $p_{\text {int }}$ occurs which deviates from the ambient pressure. The pressure difference between the pressure on the outside of the facade and the internal pressure $p_{\text {int }}$ is now decisive for the infiltration over a part of the facade. This pressure is adjusted in such a way that the difference of the inflowing and outflowing volume flows is balanced to zero:

$$
V_{\text {in }}^{\cdot}=V_{\text {out }}^{\cdot}
$$

Taking the a-values and joint lengths into account, a determination equation for the internal pressure $p_{\text {int }}$ can be derived from this, whereby with the index $i$ the partial areas are marked with an overpressure and with the index $\mathrm{j}$ the partial areas are marked with a depressure:

$$
\sum_{i}\left(p_{\text {overpressure }, i}-p_{\text {int }}\right) \cdot l_{i} a_{i}-\Sigma_{j}\left(p_{\text {depressure } j}-p_{\text {int }}\right) l_{j} a_{j}=0
$$

Thus, for each hour of the used test reference year, the volume flow through the sub-areas can be determined based on the wind pressure. Figure 4 shows the course of the average pressure difference over the building envelope.

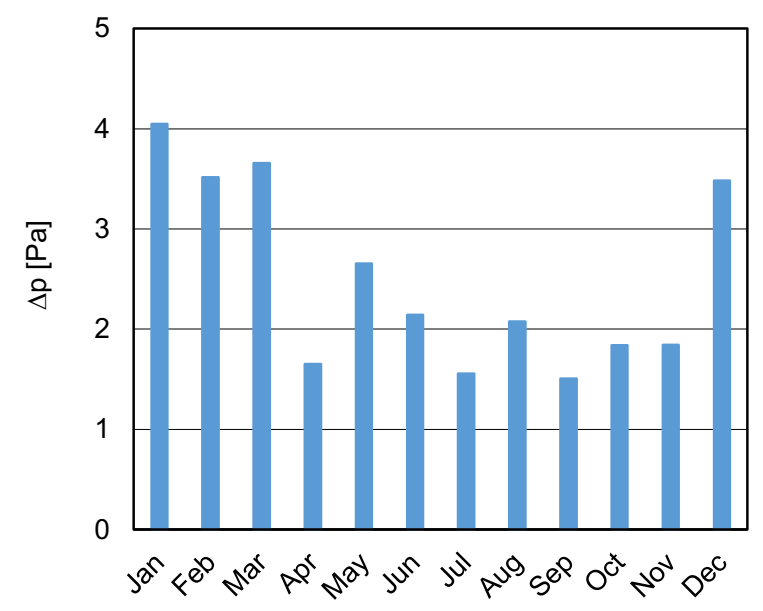

Fig. 4. Monthly average of the mean pressure differences over the building envelope due to wind

The difference in temperature inside and outside creates a thermal lift in the building. Its size depends on the height of the building and the temperature difference between inside and outside. In principle, the situation shown in Figure 5 arises, at which "overpressure" and "depressure" is indicated from inside the building.

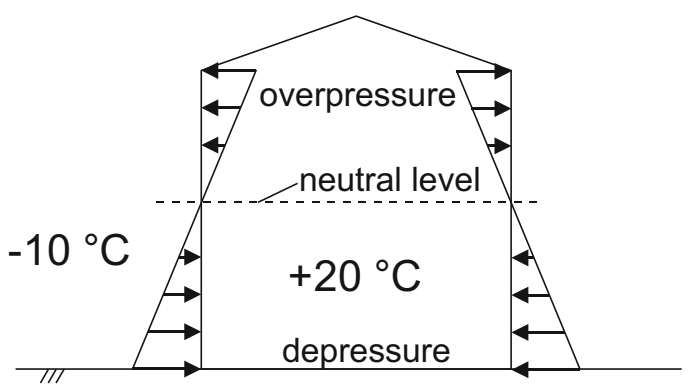

Fig. 5. Pressure distribution on the building envelope through thermal lift

Assuming that the air escapes due to the thermal lift in the upper part of the façade or roof, the pressure difference due to half of the building height results as effective air column, see Figure 6. 


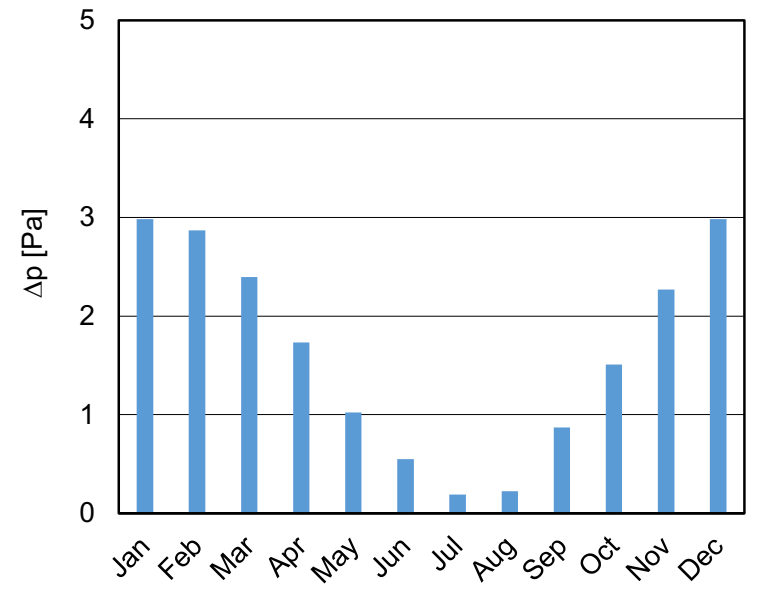

Fig. 6. Monthly average of the average pressure differences over the building envelope due to thermal lift

Finally, the effects of wind pressure and temperature difference are combined considering the meteorological data on an hourly base and the postulation according equation 1 to determine the pressure difference and the resulting airflow through the building envelope. In order to determine the energetic significance of facade tightness, this pressure difference is to be entered into the equation for the flow through a joint

$$
V^{\cdot}=a \cdot \Delta p^{2 / 3}
$$

and to be multiplied by the properties of the air (heat capacity, temperature difference).

Combining of the air volume flow with the transmission losses now allow to determine an "effective heat transfer coefficient" as described before.

\section{Application to tested panels}

Within the framework of the considerations on the effective U-values, the airtightness of the panels is decisive. Therefore, panels with standard and improved joint regarding airtightness were examined.

In addition to the standard compressible sealing tapes installed between the panels, an additional seal can be installed at the factory in the panel joint to bridge mounting tolerances and to improve the airtightness of sandwich panels. Due to its position between the steel sheets, this seal has the advantage of reliably closing the joint even without a strong horizontal compression.

\subsection{Thermal performance}

The influence on the heat transfer coefficient of the improved joint should be evaluated. For this purpose, the sandwich panel is examined by means of the Finite Element Method (FEM). Especially the influence of the improved joint, which is of great importance for airtightness, is to be considered.

In the following, the calculation results for the U-value for different panel thicknesses are given according to the exact method for the investigated sandwich panels with standard and improved joint in Table 1. In addition, the model of the numerical calculations used in the exact method as well as the determined temperature distributions are shown for a sandwich panel thickness of $100 \mathrm{~mm}$ with standard joint type III in Figure 7.

Table 1. U-values of sandwich panels, standard and improved.

\begin{tabular}{|c|c|c|c|}
\hline $\mathbf{d}[\mathbf{m m}]$ & $\begin{array}{c}\text { U-value } \\
{\left[\mathbf{W} / \mathbf{m}^{2} \mathbf{K}\right]} \\
\mathbf{w} / \mathbf{j} \text { joint } \\
\text { influence }\end{array}$ & $\begin{array}{c}\text { U-value } \\
{\left[\mathbf{W} / \mathbf{m}^{2} \mathbf{K}\right]} \\
\text { with joint } \\
\text { influence, } \\
\text { standard } \\
\text { joint }\end{array}$ & $\begin{array}{c}\text { U-value } \\
{\left[\mathbf{W} / \mathbf{m}^{2} \mathbf{K}\right]} \\
\text { with joint } \\
\text { influence, } \\
\text { improved } \\
\text { joint }\end{array}$ \\
\hline 60 & 0.366 & 0.427 & 0.430 \\
\hline 80 & 0.278 & 0.314 & 0.314 \\
\hline 100 & 0.224 & 0.249 & 0.250 \\
\hline 120 & 0.187 & 0.207 & 0.207 \\
\hline 140 & 0.161 & 0.178 & 0.178 \\
\hline
\end{tabular}

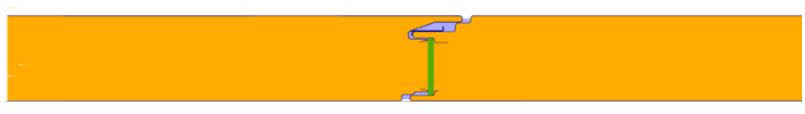

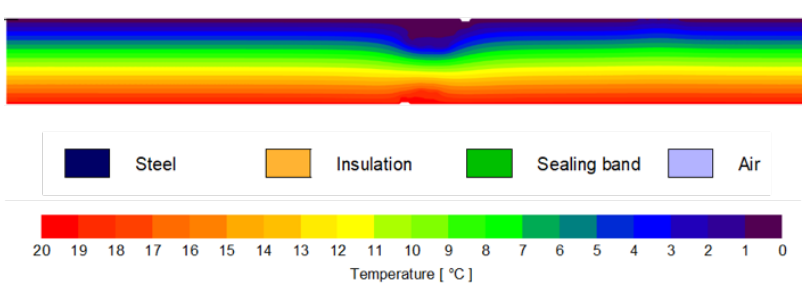

Fig. 7. FEM model and temperature distribution of sandwich panel with standard joint type III

The influence of the regular joint on the $u$-value is clearly visible for both cases (standard and improved). But furthermore it can be shown that the improved joint regarding airtightness has practically no additional influence on the design value of the heat transfer coefficient (transmission) of the sandwich panel.

\subsection{Airtightness performance}

The influence of the improved joint on the airtightness of sandwich panels was evaluated by measurement with an airtightness test rig. In order to be able to evaluate the influence of different installation situations, the tests were carried out for different visible joint distances between $6 \mathrm{~mm}$ and $10 \mathrm{~mm}$. Whereby $6 \mathrm{~mm}$ correspond to a maximum possible compression of the inner joint sealing tape. The results are presented in Figure 8. 


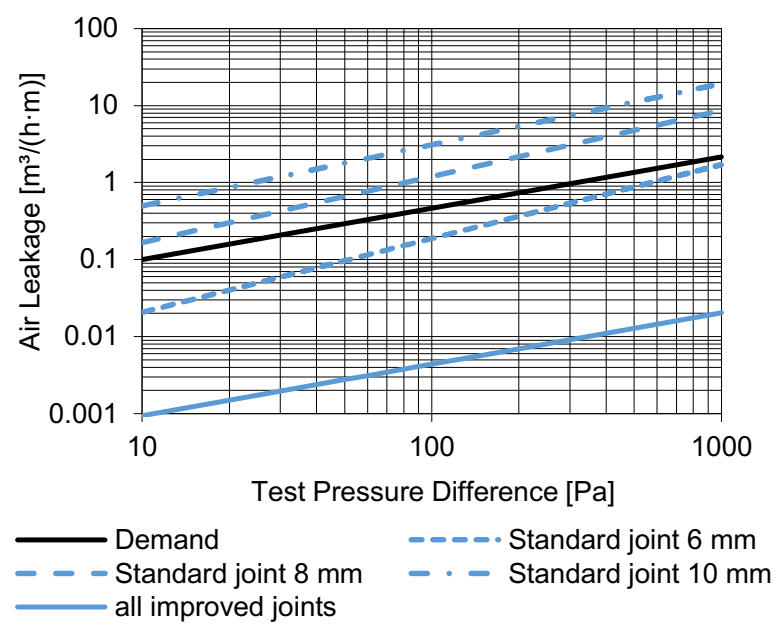

Fig. 8. Air permeability at different joint distances

The measurement of the air permeability of the joints shows that with a standard sandwich joint, the requirement value cannot be met if the installation situation deviates slightly from the ideal condition. Joints with a larger width are to be evaluated as leaky.

Regardless of the installation situation, the air permeability of the improved joint is a $=0.001 \mathrm{~m}^{3} /(\mathrm{h} \cdot \mathrm{m})$ and has an extraordinarily low air permeability at a pressure difference of $10 \mathrm{~Pa}$ compared to the standard joint. That means on the one hand that an improved joint sealing is able to bridge mounting tolerances, on the other hand nearly complete airtight joints are possible, see Figure 9.

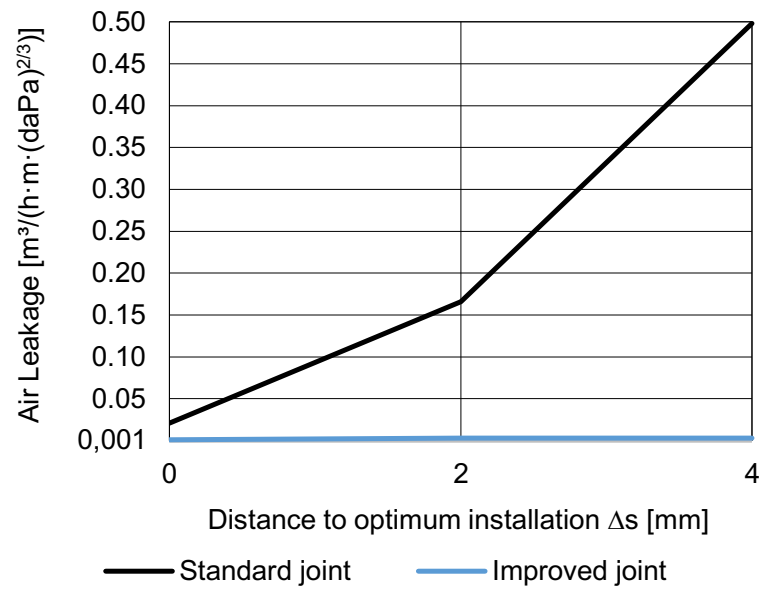

Fig. 9. Joint permeability depending on the deviation from the optimum installation condition

\subsection{Energetic and economic performance}

The correlations shown in chapter 3 allows a quick determination of an "effective heat transfer coefficient" where the infiltration losses are added to the U-value. For a very airtight joint $\left(\mathrm{a}=0.001 \mathrm{~m}^{3} /(\mathrm{h} \cdot \mathrm{m})\right.$ at $10 \mathrm{~Pa}$ pressure difference), the effective U-value practically corresponds to the design value of the heat transfer coefficient (U-value) of the sandwich element. With very leaky joints $\left(\mathrm{a}=1.0 \mathrm{~m}^{3} /(\mathrm{h} \cdot \mathrm{m})\right.$ at $10 \mathrm{~Pa}$ pressure difference) the effective heat transfer coefficient increases by approx. $U=0.20 \mathrm{~W} /\left(\mathrm{m}^{2} \mathrm{~K}\right)$, see Figure 10 .

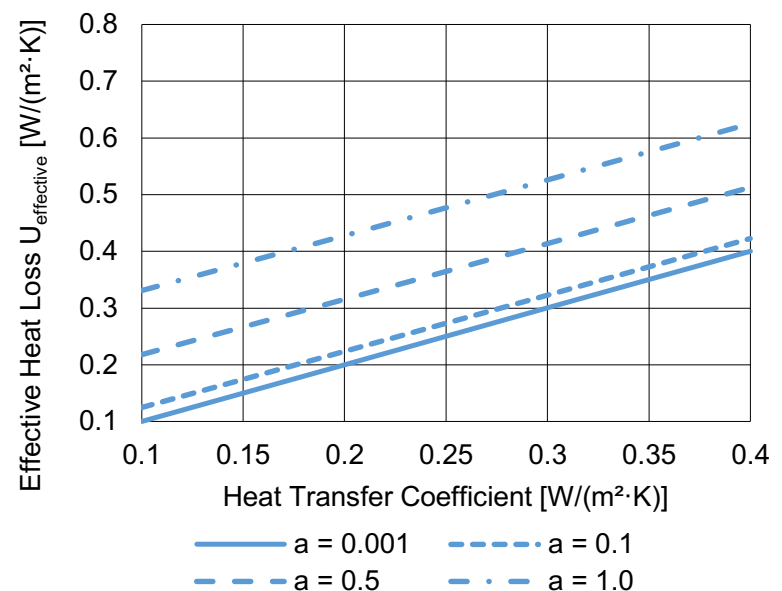

Fig. 10. Effective heat loss ( $\left.U_{\text {effective}}\right)$ depending on heat transfer (U-value) and joint airtightness (a-value)

The heating energy demand caused by the heat transfer through $1 \mathrm{~m}^{2}$ roof or wall surface cannot be specified directly. Temperature conditions, internal and external heat sources and numerous other factors influence this value, so that a more detailed calculation according different standards would be necessary for each individual case.

In order to come still to an estimation, a method of modified heating degree days (heating limit temperature dependent on the insulation standard) is used. Therefore, the same typical hall-like building ( $45 \mathrm{~m} \times 30 \mathrm{~m} \times 8 \mathrm{~m})$, is analysed to calculate a necessary heating demand.

Figure 11 shows the heating demand per $\mathrm{m}^{2}$ enveloping surface determined according to this method. The effect of a variation of heat transfer (U-value) and joint airtightness (a-value) can be read off directly in the diagram and is comparable to the effective heat losses before.

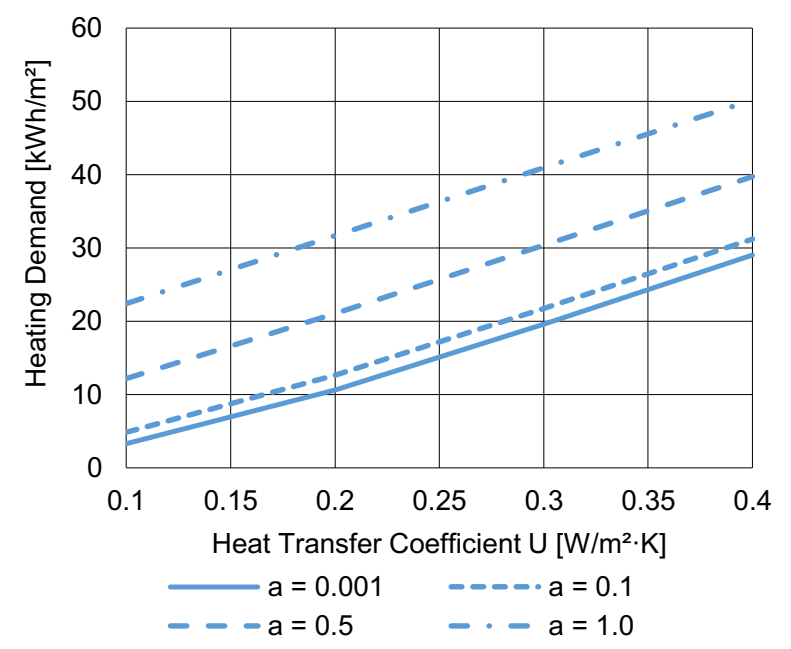

Fig. 11. Heating demand related to $1 \mathrm{~m}^{2}$ wall surface depending on heat transfer (U-value) and joint leakage (avalue) 
With knowledge of the heat prices and the heating demand determined before, the costs for the heating requirement per $\mathrm{m}^{2}$ roof or external wall surface can be determined. An example calculation with heat production costs of $0.08 € / \mathrm{kWh}$ leads to the annual heating costs shown in Figure 12 as a function of heat transmission (U-value) and joint tightness (a-value).

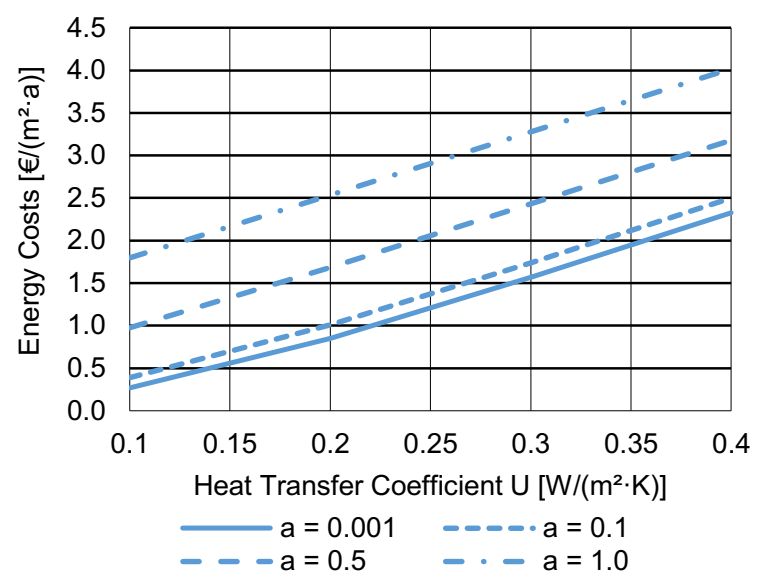

Fig. 12. Heating costs related to $1 \mathrm{~m}^{2}$ wall surface depending on heat transfer (U-value) and joint leakage (a-value) at heat production costs of $0.08 € / \mathrm{kWh}$

Depending on the $\mathrm{u}$-value of the sandwich panels, the energy costs of different airtightness scenarios can now be approximately determined. If a wall construction is realised with a heat transfer (U-value) of $0.15 \mathrm{~W} / \mathrm{m}^{2} \mathrm{~K}$ (160 mm PU core), this results in heating costs of 0.51 $€ / \mathrm{m}^{2} \mathrm{a}$ for a very airtight design $(\mathrm{a}=0.001$ $\mathrm{m}^{3} /\left(\mathrm{h} \cdot \mathrm{m} \cdot(\mathrm{daPa})^{2 / 3}\right)$ and a heat price of $0.08 € / \mathrm{kWh}$. However, in the case of a very leaky design, heating costs of more than $2.00 € / \mathrm{m}^{2}$ are incurred.

\section{Conclusions}

The investigations have shown that the influence of the airtightness of a facade has a considerable influence on the energy demand of a building. The prefabricated steel sandwich panels are absolutely airtight in the area of the metal cover layers. The sealing of the component joints contributes to fulfil the comprehensive requirements for an airtight building envelope. It could be shown that the goal of an air-impermeable facade can also be achieved in steel sandwich constructions by using optimised joint sealing strategies.

A way was shown how to combine the energy losses through the infiltration with the transmission losses taking into account determined pressure differences across an exemplary building due to wind and temperature differences. By determining of this "effective U-value" that takes into account both transmission and infiltration, the effect of a permeable façade can be clearly shown by change of the design Uvalue. This was converted into a heating demand and the advantages of an airtight construction was demonstrated also regarding occurring energy costs.

\section{References}

1. Kuhnhenne, M., Brieden, M., Ungermann, D., Wiegand, A. Building redevelopment Solutions for roof and façade using lightweight steel construction, Stahlbau 2017; 86: 862-872.

2. EN 14509:2013 Self-supporting double skin metal faced insulating panels - Factory made products - Specifications. 2013.

3. EN 13789:2018 Thermal performance of buildings - Transmission and ventilation heat transfer coefficients - Calculation method. 2018.

4. Kuhnhenne, M., Döring, B., Feldmann, M. Principles and solutions of thermal bridge reduction in light metal construction, Stahlbau 2010; 79: 345-355.

5. DIN EN ISO 10211 - Thermal bridges in building construction - Heat flows and surface temperatures - Detailed calculations. 2018.

6. Kuhnhenne, M., Brieden, M., Ungermann, D., Wiegand, A. New Solutions for energetic improvement of building envelopes in lightweight steel - in addition to the publication in Stahlbau 86 (2017), issue 10, Stahlbau 2018; 87: 1072-1083.

7. Laukkarinen, A., Vinha, J., Kalamees, T., Kalbe, K., Honkakoski, E., Kesti, J. Laboratory tests and modelling of mineral wool insulated steel sandwich panels, in NSB 2020 12th Nordic Symposium on Building Physics (0609.09.2020, Tallinn, Estonia., 2020)

8. DIN 4108-4:2013 Thermal protection and energy economy in buildings - Part 2: Minimum requirements to thermal insulation. 2013.

9. DIN 18542: 2019 Sealing of outside wall joints with impregnated sealing tapes made of cellular plastics - Impregnated sealing tapes Requirements and testing. 2019.

10. EN 12114:2000 Thermal performance of buildings - Air permeability of building components and building elements - Laboratory test method. 2000.

11. Kemper, F., Funke, A., Kuhnhenne, M., Feldmann, M. Appraisement of complex wind load effects on the building envelope, Stahlbau 2017; 86: 907-916.

12. EN 1991-1-4:2010 Eurocode 1: Actions on structures - Part 1-4: General actions - Wind actions. 2010.

13. EN 1991-1-4/NA National Annex - Nationally determined parameters - Eurocode 1: Actions on structures - Part 1-4: General actions - Wind actions. 2010. 